\title{
O trabalho de luto e o trabalho com o luto: percepção de estagiários de enfermagem sobre a morte e o morrer junto a pacientes hospitalizados
}

The work of mourning and the work with mourning: perception of nursing interns about death and dying with hospitalized patients

El trabajo de duelo y el trabajo de duelo: percepción de la muerte y el morir de los internos de enfermería con los pacientes hospitalizados 


\begin{abstract}
Resumo
Cientificamente, a morte é um evento biológico, natural e inevitável que caracteriza o final da vida, sendo considerada a falência irreversível do funcionamento dos órgãos. Este estudo objetivou investigar como o estagiário de enfermagem lida com o processo de morte e luto. Trata-se de uma pesquisa de campo, do tipo descritiva-exploratória, transversal, com abordagem qualitativa, realizada em um hospital geral e em uma maternidade localizados em um município do estado do Maranhão. A amostra foi composta por 10 estagiários de enfermagem. Como resultado constatou-se que os estagiários de enfermagem possuem dificuldades em lidar com a morte e o luto. Os principais sentimentos despertados diante da morte foram a impotência, tristeza, fracasso, frustração, dor, angústia e frieza. Assim, para se proteger, os acadêmicos criam estratégias, das quais se destacam a aceitação, racionalização, religiosidade, distanciamento e negação. Percebeu-se, também, que a compreensão deles frente a finitude da vida está relacionada às experiências pessoais de cada um, entretanto, notou-se que a morte de crianças, jovens e pacientes oncológicos são as mais difíceis de lidar. Conclui-se, em razão dos aspectos mencionados, a importância de introduzir na grade curricular disciplinas que abordem o processo de morte/morrer e luto. Recomenda-se que o estagiário de enfermagem busque realizar cursos, pós-graduações e especializações ao decorrer de sua vida profissional, a fim de adquirir aprendizados sobre como lidar com situações de terminalidade, prestando assistência de qualidade e compartilhando conceitos e experiências.
\end{abstract}

Palavras-chave: Morte; Luto; Enfermagem.

\begin{abstract}
Scientifically, the death is a biological, natural and inevitable event that characterizes the end of life, being considered the irreversible collapse of the functioning of organs. This study objectified to investigate how the nursing trainee deals with the process of death and mourning. This is a descriptive-exploratory cross-sectional field research, with a qualitative approach, performed in a general hospital and in a maternity hospital located in a municipality in the state of Maranhão. The sample consisted of 10 nursing trainees. As result, it was found that nursing trainees have difficulties dealing with death and mourning. The main feelings awakened against death were impotence, sadness, failure, frustration, pain, anguish, and coldness. So, to protect themselves, the academics create strategies, of which the acceptance, rationalization, religiosity, distancing and negation stand out. It was also realized that their understanding of the finitude of life is related to the personal experiences of each one, however, it was noted that the death of children, young people and cancer patients are the most difficult to deal with. It is concluded, due the mentioned aspects, the importance of introducing disciplines in the curriculum that approaches the process of death / dying and mourning. It is recommended that the nursing trainee search to accomplish classes, post-graduations and specializations during his professional life, in order to obtain knowlegde about how to deal with terminal situations, providing quality assistance and sharing concepts and experiences.
\end{abstract}

Keywords: Death; Bereavement; Nursing.

\title{
Resumen
}

Científicamente, la muerte es un evento biológico, natural e inevitable que caracteriza el final de la vida, considerándose el fallo irreversible de funcionamiento de los órganos. Este estudio tuvo como objetivo investigar cómo el interno de enfermería afronta el proceso de muerte y duelo. Se trata de una investigación de campo, descriptiva-exploratoria, transversal, con abordaje cualitativo, realizada en un hospital general y en una maternidad ubicada en un municipio del estado de Maranhão. La muestra estuvo compuesta por 10 pasantes de enfermería. Como resultado, se encontró que los internos de enfermería tienen dificultades para lidiar con la muerte y el dolor. Los principales sentimientos que se despertaron ante la muerte fueron el desamparo, la tristeza, el fracaso, la frustración, el dolor, la angustia y la frialdad. Así, para protegerse, los académicos crean estrategias, de las que destacan la aceptación, la racionalización, la religiosidad, el desapego y la negación. También se notó que su comprensión de la finitud de la vida está relacionada con las experiencias personales de los demás, sin embargo, se señaló que las muertes de niños, jóvenes y pacientes con cáncer son las más difíciles de manejar. Se concluye, por los aspectos mencionados, la importancia de introducir en el currículo asignaturas que abordan el proceso de muerte / morir y duelo. Se recomienda que el pasante de enfermería busque realizar cursos, posgrados y especializaciones a lo largo de su vida profesional, con el fin de adquirir lecciones sobre cómo enfrentar situaciones terminales, brindando asistencia de calidad y compartiendo conceptos y experiencias.

Palabras clave: Muerte; Duelo; Enfermería.

\section{Introdução}

Cientificamente, a morte é um evento biológico, natural e inevitável que caracteriza o final da vida, sendo considerada 
a falência irreversível do funcionamento dos órgãos, o que faz com que o organismo não seja capaz de manter suas necessidades básicas. Entretanto, o conceito de morte é algo relativo, complexo e mutável, dependendo da formação religiosa, cultural e da situação afetiva de cada pessoa (Benedetti, Oliveira, Oliveira, Sales, \& Ferreira, 2013).

Em decorrência do avanço da medicina, a morte passou a ser cada vez mais hospitalizada, fazendo, muitas vezes, com que o trabalho da equipe de saúde seja percebido como frustrante e desmotivador. Segundo alguns estudos, a negação, ou seja, evitar falar sobre o fim da vida, é o mecanismo de defesa mais utilizado pelos profissionais para se proteger de experiências dolorosas (Rosa \& Couto, 2015). Pesquisas evidenciam, ainda, que ocorre um sofrimento maior quando o processo de terminalidade acontece em crianças e jovens (Benedetti et al., 2013).

Cuidar de pacientes em processo de morrer no campo hospitalar é uma ação realizada frequentemente pela equipe de saúde, sobretudo pelo grupo de enfermagem, que permanece maior tempo em interação com o paciente, sendo também indispensável no processo do luto, no sentido de prover apoio e amparo à família deste (Salum et al., 2017).

A formação acadêmica do futuro enfermeiro o instrui a zelar pela vida do paciente, recuperando e promovendo sua saúde, sem considerar o enfrentamento da morte. A inexistência de uma preparação específica para enfrentar este acontecimento pode ocasionar no graduando um impacto emocional e problemas psicológicos devido às limitações de discussões teóricas sobre o assunto (Sartori \& Battistel, 2017).

Diante disso, abordar essa temática é de suma importância para o meio acadêmico, haja vista estimular nos estudantes a consciência de que, embora, como profissionais de enfermagem, sejam comprometidos com a vida e atuem em prol do restabelecimento da saúde, nem sempre é uma tarefa possível, ultrapassando seus desígnios. Assim, é preciso trabalhar seu emocional, discutindo de forma mais ampla a temática morte durante sua formação acadêmica.

Este estudo teve como problemática: “Como o estagiário de enfermagem lida com o processo de morte e luto?". Para tal, objetivou-se, de forma geral, investigar como o estagiário de enfermagem lida com o processo de morte e luto, e de maneira específica: compreender os sentimentos vivenciados pelo estagiário de enfermagem frente à morte do paciente; descrever as estratégias de cuidado emocional que os estagiários utilizam para conviver com a morte no ambiente hospitalar; e identificar o que os estagiários de enfermagem citam como necessário para obter preparo para lidar com a morte no ambiente profissional.

\section{Metodologia}

Trata-se de uma pesquisa de campo, do tipo descritiva-exploratória, transversal, com abordagem qualitativa. De acordo com Potter e Perry (2013) a pesquisa qualitativa tem como objetivo descrever de modo não numérico os dados coletados e analisar fenômenos que são difíceis de dimensionar ou categorizar. Esse tipo de estudo fornece resultados através da compreensão da vivência dos indivíduos, onde eles possuem a chance de expor suas experiências. Nessa forma de pesquisa, utiliza-se o raciocínio indutivo para criar teorias baseadas em observações ou entrevistas, gerando assim, um maior entendimento do fenômeno abordado.

Quanto ao local, ela foi realizada em um hospital geral e em uma maternidade, ambos localizados em um município do estado do Maranhão, onde estes foram escolhidos por consistirem de locais que abrangem uma grande quantidade de estagiários de enfermagem em diversas áreas, como cirurgia, Unidade de Terapia Intensiva (UTI), neonatal, entre outros, o que viabiliza e facilita a realização dessa pesquisa.

A pesquisa foi realizada com estagiários do curso de bacharelado em enfermagem em estágio hospitalar e que já vivenciaram alguma experiência com o tema proposto para o estudo, ou seja, que já vivenciaram a morte de algum paciente. A partir das listas fornecidas pelas instituições participantes da pesquisa, os estagiários foram escolhidos para participar do estudo por meio de sorteio. 
Os critérios de inclusão foram: ser estagiário do curso de bacharelado em enfermagem; já ter vivenciado o processo de morte e morrer de algum paciente; e estar em estágio dentro do ambiente hospitalar. Já os critérios de exclusão foram: estudantes de outras graduações; estagiários de enfermagem que não tiveram experiências com o processo de morte e morrer; e estudantes que não estavam em estágio hospitalar.

Foram encontrados 13 estagiários de enfermagem que se encaixavam nos critérios de inclusão, porém três não aceitaram participar do estudo, então, a amostragem final da pesquisa contou com dez participantes. Como delimitação do número de entrevistas se levou em consideração o conceito de saturação de dados.

O processo de coleta de dados foi realizado por meio da aplicação de um questionário contendo uma parte inicial de caracterização dos sujeitos, com dados sociodemográficos, e outra parte com perguntas abertas. O questionário e a entrevista semiestruturada foram realizados individualmente, de modo que a entrevista foi registrada mediante gravação, em áudio, com a autorização do entrevistado, tendo as respostas transcritas de forma fidedigna para, em seguida, realizar a análise qualitativa e interpretação dos dados colhidos.

Assim, após esse processo, os estagiários de enfermagem sorteados foram contatados por meio de um convite verbal e após concordarem participar do estudo, foi disponibilizado o termo de consentimento livre e esclarecido (TCLE) segundo as normas da Resolução no 466/12 do Conselho Nacional de Saúde (CNS) sobre as pesquisas que envolvem seres humanos, sendo, ainda, garantida a preservação da identidade dos participantes.

Os questionamentos da entrevista avaliaram as características dos entrevistados; definição do processo de mortemorrer; os sentimentos gerados pelo enfrentamento desse processo; os meios de enfrentamento utilizados por eles e o que é necessário para lidar com a morte dos pacientes; assim como os impactos causados pela vivência dessas situações. As entrevistas duraram em média de 30 a 40 minutos e o período de coleta ocorreu entre os meses de março e abril de 2019.

Este projeto de pesquisa foi submetido à Plataforma Brasil e encaminhado ao Comitê de Ética e Pesquisa do Centro Universitário de Ciências e Tecnologia do Maranhão - UniFacema. A pesquisa ocorreu de acordo com a Resolução do Conselho Nacional de Saúde $n^{\circ}$ 466/12, sob o CAAE (Certificado de Apresentação para Apreciação Ética) $n^{\circ}$ 09461319.3.0000.8007, objetivando garantir os direitos e deveres dos participantes da pesquisa, em que refere-se à aceitação e assinatura do TCLE pelos estagiários de enfermagem, onde nele estava expresso os objetivos da pesquisa, benefícios, riscos e os procedimentos que foram realizados para minimizá-los.

\section{Resultados e Discussão}

A apresentação dos resultados e discussão foi estruturada em duas etapas: a primeira refere-se à caracterização dos sujeitos participantes da pesquisa, e a segunda relaciona-se ao cumprimento dos objetivos do estudo, através da exposição dos depoimentos e análise dos mesmos.

A aplicação do instrumento de coleta de dados permitiu a realização da caracterização dos sujeitos que participaram da pesquisa, abordando variáveis sociodemográficas que incluíam sexo, idade, período do curso, estado civil, religião e préformação.

A amostra foi constituída por dez estagiários de enfermagem, destes, seis (60\%) eram do sexo feminino e quatro (40\%) do sexo masculino. No que diz respeito à idade, a faixa etária variou de 21 a 29 anos, onde seis (60\%) dos entrevistados possuíam entre 21 e 25 anos e quatro (40\%) possuíam idade entre 26 e 29 anos. Em relação ao período do curso, os dez (100\%) participantes relataram estar cursando o décimo período da faculdade. No que se refere ao estado civil, somente um (10\%) dos entrevistados era casado, os outros nove (90\%) afirmaram serem solteiros.

No que concerne à religião dos participantes, seis $(60 \%)$ eram católicos e quatro $(40 \%)$ eram protestantes. Quando perguntados se possuíam alguma pré-formação, cinco (50\%) dos estagiários afirmaram não ter nenhuma pré-formação, e os 
outros cinco (50\%) relataram ter como pré-formação o curso técnico de enfermagem.

\section{As classes e suas descrições}

As informações adquiridas a partir das entrevistas com os estagiários foram expostas mediante as falas mais relevantes. Como garantia do sigilo e anonimato dos participantes, estes foram representados pela palavra "Entrevistado" e por números, no intuito de designar a sequência em que as entrevistas foram realizadas (Entrevistado 1, Entrevistado 2...).

Dessa forma, buscando atingir os objetivos propostos nesta pesquisa, a análise dos dados permitiu a construção de cinco classes: Classe 1 - Significado de morte e morrer para os estagiários de enfermagem; Classe 2 - Sentimentos vivenciados pelos estagiários de enfermagem frente à morte do paciente; Classe 3 - Estratégias de cuidado emocional para conviver com a morte no ambiente hospitalar; Classe 4 - O preparo para lidar com a morte no ambiente profissional; Classe 5 - O processo de morte e morrer como prejuízo emocional aos estagiários de enfermagem.

\section{Classe 1: Significado de morte e morrer para os estagiários de enfermagem}

Sobre o significado do processo de morte e morrer, identificou-se, sobretudo, certa insegurança e inquietação ao abordar de forma direta o assunto. Os estagiários de enfermagem, quando interrogados, relataram diferentes percepções e diversos entendimentos de acordo com os aspectos individuais e religiosos de cada um, dentre os quais destaca-se a compreensão da morte como um processo natural da vida e algo inevitável ao ser humano, como mostra as falas dos participantes:

A morte ela é um processo natural que todos nós estamos sujeitos. (Entrevistado 2)

A morte é um processo natural, que todo ser humano vai passar por ele [...], mesmo sendo um processo natural é um processo difícil e doloroso que sempre vai mexer com meu emocional. (Entrevistado 3)

Morte é o momento inevitável da vida e que querendo ou não a gente vai ter contato com esse processo. (Entrevistado 7)

Segundo Benedetti, Oliveira, Oliveira, Sales e Ferreira (2013), compreender a morte como algo natural e inevitável é assumir que a vida tem um início, um meio e um final, sendo uma forma de encarar a finitude de modo racional e harmônico. Apesar da morte ser percebida como uma ocorrência aceitável e pertencente a todo ser humano, percebe-se que, mesmo assim, ela causa dor, sofrimento e desconforto a quem a vivencia.

Além da morte como processo natural, outra interpretação que também se destacou e foi bastante citada pelos estagiários foi a compreensão do morrer como uma transição espiritual, passagem para uma outra vida ou missão cumprida, sendo enfatizado também que o difícil é lidar com o pós-morte.

Eu encaro a morte como um processo de passagem. Apesar de ser difícil conviver com ela ou vivenciar ela, pra mim o que é mais difícil na morte é conviver com a ausência da pessoa, mas eu não encaro a morte como algo muito ruim. (Entrevistado 1)

Tem um significado de passagem, é onde se encerra a jornada aqui na terra e começa um novo ciclo só que espiritual. (Entrevistado 9)

Morte pra mim é o processo onde o indivíduo termina sua missão. (Entrevistado 10)

Frente a esses achados, busca-se nessa forma de representação, atenuar a dor e o pesar, procurando na crença respostas para entender o desconhecido e amenizar as dúvidas que a morte traz (Oliveira et al., 2016). 
Ressalta-se ainda que, embora a maioria dos participantes não considere a morte como algo ruim, observou-se também que duas falas se opuseram a essa representação, onde os entrevistados definiram o fim da vida como algo negativo, como mostra as declarações a seguir:

\section{É algo terrível, algo que ninguém nunca tá preparado pra passar. (Entrevistado 6)}

Morte é algo que não sabemos o significado de certo, é a perda de algo que não será bom, mesmo sabendo as vezes que não tem como evitar. (Entrevistado 8)

Com esses relatos, percebe-se a manifestação de sentimentos obscuros, no qual não se consegue enfrentar o processo de morte e morrer de modo menos impactante, constatando-se que o significado da morte ainda se revela como uma barreira para os estagiários, mesmo tendo o entendimento de que é algo comum a todos os seres.

Para Sant'Ana, Santos, Menezes, Pereira e Santana (2013), ter dificuldades para lidar com esse processo se deve ao fato de, nos dias de hoje, essa temática ainda ser vista como um tabu, fazendo assim, com que ela seja temida e negada. Ademais, uma representação negativa diante da morte se associa também a um déficit na abordagem do tema no decorrer da graduação.

\section{Classe 2: Sentimentos vivenciados pelos estagiários de enfermagem frente à morte do paciente}

Nesta categoria, observou-se por meio dos relatos dos estagiários de enfermagem que os sentimentos vivenciados perante a morte do paciente são diversos, sendo possível perceber que as falas dos sujeitos se apresentaram de forma dicotômica.

Dos dez entrevistados, seis relataram sentimentos de tristeza, pesar, dor, angústia, impotência, frustração e fracasso; três não souberam definir seus sentimentos e um relatou calosidade profissional. Mencionaram, ainda, o vínculo construído com os pacientes e a dificuldade em lidar com os familiares destes quando o processo de morte e morrer acontece, como mostra os depoimentos a seguir:

Ao vivenciar essa experiência da morte do paciente, primeiro sentimento que vem é o sentimento de impotência, porque você acredita que não foi bom o suficiente e o paciente veio a falecer diante de você, diante dos seus cuidados, e é muito triste. (Entrevistado 1)

É um sentimento bastante doloroso. (Entrevistado 3)

Cada paciente é um caso e cada caso tem sua especificidade, e depende muito do teu convívio com aquele paciente [...]. Na verdade, o difícil não é lidar com o paciente e sim com o familiar, na hora de dar o laudo vai uma equipe toda preparada para lidar com a familia e não com o paciente. (Entrevistado 5)

No primeiro momento a gente fica meio em choque, [...] tentando resolver a situação, depois que a gente fez tudo que pode aí a gente tem o sentimento de pesar, porque a gente teve um vínculo querendo ou não. (Entrevistado 7)

Sentimento de tristeza, angústia, frustração pelo fato de ter feito algo para ajudar a pessoa e não ter conseguido. (Entrevistado 8)

De princípio é um sentimento de fracasso, é como se você pudesse ter feito alguma coisa a mais para poder prolongar a vida do paciente em questão [...]. O mais difícil, sem dúvidas, é lidar com a reação dos familiares. (Entrevistado 9)

Verifica-se, através dessas falas, que esses achados corroboram com outras pesquisas similares. Segundo o estudo realizado por Oliveira et al. (2016), com estudantes de enfermagem do estado da Paraíba, os sentimentos mais citados frente ao processo de morte e morrer foram tristeza, angústia, dor e impotência. Pesquisas internacionais na área, também apresentam 
resultados semelhantes, como no estudo realizado por Muñoz-Pino (2014), com graduandos de enfermagem, no Chile, onde os sentimentos mais frequentemente expressados foram a angústia, tristeza e a frustração.

Para Huber, Salvaro, Medeiros e Soratto (2017), a tristeza e o pesar são sensações naturais diante do enfrentamento da finitude da vida; o enfermeiro que se emociona com tal situação demonstra empatia e não falta de controle, pois é necessário entender que isso faz parte da estrutura emocional do ser humano. Nesses casos, o sentimento de luto sempre se faz presente, definindo-se por manifestações psicológicas que ocasionam sofrimento, angústia e dor (Freitas et al., 2016).

Conforme Huber et al. (2017), a sensação de fracasso, impotência e frustração se devem ao fato dos graduandos de enfermagem atuarem a favor da cura, e estão intimamente relacionadas à falha na educação sobre a temática durante a graduação, que visa somente a promoção, recuperação e preservação da vida. Então, quando isso não é possível, a morte é entendida como uma derrota, pois na visão deles não se realizou intervenções eficientes.

Como relatado anteriormente, o vínculo entre estagiário e paciente foi bastante citado pelos entrevistados como algo que influencia nos sentimentos expressos por eles. Resultado semelhante foi encontrado por Nunes, Araújo e Silva (2016), que relatam que o laço afetivo criado entre o estagiário e o paciente no decorrer dos cuidados prestados, é um dos principais elementos que intervêm na expressão dos sentimentos provenientes do processo de morte e morrer. Por conseguinte, quando o paciente vem a óbito o sofrimento é inevitável.

A equipe de enfermagem é quem tem mais contato com o paciente, se tornando também suporte para a familia, o que, consequentemente, acarreta um maior envolvimento e sofrimento para o profissional (Araújo, Álvares, \& Jesus, 2018).

Embora seja evidente que a morte traz sentimentos geradores de sofrimento psíquico, o convívio diário com ela faz com que alguns estagiários passem a encará-la com naturalidade, negando seus sentimentos, como mostra a fala de um dos entrevistados:

No começo a gente fica muito sentido, do meio pro fim já fica tipo que natural, a gente perde um pouquinho a empatia, não vou mentir, porque são tantas pessoas morrendo. (Entrevistado 2)

Segundo Salum et al. (2017), em razão da realização de regulamentos e rotinas, é preciso se atentar para não perder a sensibilidade e empatia, pois são os principais pontos necessários na atenção ao paciente frente à morte. Dessa forma, o estagiário nega seus sentimentos por julgar que o profissional competente é aquele que tem certa frieza em suas atitudes (Pereira, Carvalho, Vale, Silva, \& Morais, 2014).

\section{Classe 3: Estratégias de cuidado emocional para conviver com a morte no ambiente hospitalar}

A classe 3 discorre sobre as estratégias emocionais, também chamadas de mecanismos de defesa que os estagiários de enfermagem utilizam para coexistir com a morte no ambiente hospitalar. Foi observado que os entrevistados não possuem preparo emocional suficiente para lidar com essa temática, onde alguns relatam não ter nenhuma estratégia emocional para tal situação.

Dos dez participantes, cinco declararam que o mecanismo usado por eles é a aceitação e a racionalização de que fizeram tudo o que estava ao seu alcance. Além disso, a promoção do conforto ao paciente também foi citada como meio de conviver com a presença da morte e amenizar o sentimento de impotência.

O que eu utilizo pra conviver sabendo que um paciente meu vem a falecer diante dos meus cuidados é analisar a situação em que ele se apresentou e muitas vezes a gente não pode interferir [...]. Então é você aceitar a condição do paciente e saber que você não podia fazer nada, na maioria das vezes o que acontece é isso. (Entrevistado 1)

Acho que antes de pensar na morte é pensar nas chances de cura que aquele paciente vai ter né, a partir do momento 
que a gente faz de tudo pra que ele não venha a óbito é mais complicado, mas a gente tenta mantê-lo calmo na medida do possível, dizer que vai ser feito todos os procedimentos e os sentimentos acabam sendo controlados assim. (Entrevistado 4)

Não é que tu tem uma estratégia, é que querendo ou não tem que aprender a lidar [...]. Pensar que você fez tudo que podia te ampara. (Entrevistado 5)

Primeiro eu me autoavalio, vejo o que eu poderia fazer, o que eu fiz, o que estava ao meu alcance, e eu procuro refletir se poderia ter feito mais por aquele paciente. (Entrevistado 7)

Tento não deixar o emocional pesar em mim. Procuro pensar que fizemos de tudo, porém não foi com sucesso. (Entrevistado 8)

É sabido que os mecanismos de defesa são necessários para enfrentar as situações de morte e morrer, e que alguns são utilizados de forma inconsciente. De acordo com Lamb et al. (2017), o suporte na compreensão de dever cumprido atua como forma de racionalizar seus sentimentos, fazendo com que os estagiários se convençam de que não existe motivo para sofrer, dado que eles forneceram o máximo de assistência possível.

Oposto a isso, observou-se também que dois dos entrevistados relatam a frieza e o distanciamento como estratégias de cuidado emocional. Desse modo, de certa forma, a morte passa a ser negada por eles como meio de defesa, o que é evidenciado nos depoimentos a seguir:

Tento ao máximo ser fria, mas não tem como não sentir pelo paciente e pela familia [...]. Pode ser que na vivência eu crie uma forma de lidar com essas coisas, por enquanto, ainda não consigo lidar muito bem, posso não demonstrar na hora, mas dentro de mim me sinto muito mal, pincipalmente quando chego em casa. (Entrevistado 6)

Não me envolvo muito afetivamente com o paciente, e tento acreditar que tudo acontece por um propósito. (Entrevistado 9)

Os achados do estudo correspondem ao que Santos e Moreira (2014) propuseram quando relataram que um dos mecanismos de defesa mais utilizados é o controle das emoções para tentar minimizar o sofrimento, entretanto, nem sempre se consegue bons resultados. Frequentemente, a frieza funciona como uma proteção do desequilíbrio emocional que a morte pode causar (Pereira et al., 2014). Sendo assim, nota-se que os estagiários não se permitem viver o luto, pois se sentem despreparados para lidar com suas emoções, utilizando o distanciamento como escudo para prevenção da dor (Nunes, Araújo, \& Silva, 2016).

Detectou-se, nesse estudo, que todos os entrevistados relataram ter uma religião. Diante disso, a espiritualidade e a crença religiosa também estiveram presentes nas falas dos depoentes como outra estratégia de cuidado emocional utilizada por eles para enfrentar a finitude da vida dos pacientes, como mostra os trechos a seguir:

A religião nesse momento ela é fundamental. Sou muito grata a Deus por ele me usar nesse ambiente, muitas vezes me deparei com pessoas que já estavam desacreditadas [...]. (Entrevistado 3)

A partir do momento que a gente tem o consentimento que todos nós um dia vamos morrer, esse elo religioso com certeza nos amadurece espiritualmente, saber que isso é algo cronológico da vida de cada um e quando isso acontece a gente acaba compreendendo. (Entrevistado 4)

Consoante a esses relatos, o estudo feito por Sartori e Battistel (2017), no Rio Grande do Sul, com acadêmicos de enfermagem, também demonstra que a religião é utilizada como forma de conforto diante da morte dos pacientes. A espiritualidade age aliviando a dor e o sofrimento, sendo um suporte que auxilia na aceitação da finitude da vida (Nunes et al., 2016). Segundo Benedetti et al. (2013), as crenças religiosas permitem que se atribua um significado às dúvidas existenciais 
que surgem diante do processo do morrer.

\section{Classe 4: O preparo para lidar com a morte no ambiente profissional}

Os estagiários de enfermagem quando questionados sobre o que eles consideram ser necessário para obter preparo diante da morte no ambiente profissional, citaram que a faculdade deveria ser a principal provedora de tal preparo, porém destacaram que há uma deficiência nos cursos de enfermagem em abordar a temática, como mostram os relatos a seguir:

Eu acho que preparar o profissional seria de suma importância, porque todo profissional vai passar por isso e o processo de morte e morrer é algo muito sério, tem que ter todo um cuidado mesmo com o paciente após a morte e a gente não recebe isso em nenhum lugar [...]. O que se vê na graduação é algo muito pincelado, é algo muito rápido, é um assunto no meio de uma matéria, é algo muito curto, ele não abrange a fundo um assunto que é tão importante quanto esse. (Entrevistado 1)

É necessário ter um preparo técnico tanto na faculdade e uma pós-graduação, muita leitura de artigo, porque realmente o profissional fica desleixado nesse processo de morte e morrer do paciente. (Entrevistado 2)

Tudo se inicia na vida acadêmica, quando a gente coloca em prática tudo que aprendeu na teoria, quando a gente aprofunda nossos conhecimentos técnicos, quando a gente tá no ambiente hospitalar acaba sendo menos dificultoso. (Entrevistado 4)

Estudos realizados por Bandeira, Cogo, Hildebrandt e Badke (2014), com docentes de enfermagem, evidenciam também uma falha no preparo dos acadêmicos em relação à vivência do processo de morte/morrer e luto, ocorrendo, na maioria das vezes, somente no campo prático, o que faz com que haja um predomínio de ações tecnicistas na atenção humanizada. No entanto, há a necessidade acadêmica de preparar o aluno sobre a tanatologia, discutindo sobre a temática durante o curso (Freitas et al., 2016).

Menin e Pettenon (2015) recomendam uma reforma na grade curricular do curso de enfermagem por meio da implantação de disciplinas e espaços para refletir sobre a morte e o luto. Similar a isso, Bandeira et al. (2014), relatam que a elaboração de uma Disciplina Complementar de Graduação (DCG) que aborde o tema seria de grande utilidade, porém insuficiente, pois é algo que deve ser discutido durante toda graduação, sendo importante, sobretudo, orientar os docentes para uma abordagem adequada.

\section{Classe 5: O processo de morte e morrer como prejuízo emocional aos estagiários de enfermagem}

A classe 5 apresenta as respostas expressas pelos estagiários de enfermagem quando interrogados sobre qual processo de morte e morrer causava maior prejuízo emocional para eles. Pela extração das falas, observou-se que as mortes de crianças e jovens são as que causam maior impacto, notando-se, também, certa comoção ao abordar o assunto e relembrar experiências.

Eu sempre me sinto muito mexida quando eu perco um paciente jovem: criança ou alguém da minha idade [...], perder uma pessoa que tinha tanta coisa pra viver é algo muito conflitante pra entender, por que tu fica imaginando o tempo todo que aquela pessoa tinha muita coisa pra viver, e não construiu nada e tu te imagina no lugar dele ou imagina alguém muito querido, torna a experiencia ainda mais difícil. (Entrevistado 1)

Criança, porque é uma vida que tá começando [...]. Quando o paciente é uma criança o impacto é maior, não tem como não chorar mesmo que não chore na frente do familiar. (Entrevistado 5)

Criança, porque quando é idoso você sabe que é algo inevitável, você envelhecer e morrer é o único caminho que a gente tem [...], então a gente até lida um pouco melhor, agora quando é criança, não sei se é pelo fato de eu ser mãe, mas mexe muito comigo. Criança não tem defesa nenhuma, não tem como se proteger, isso que mexe mais comigo. (Entrevistado 6) 
De jovens, porque me coloco no lugar deles e eu ainda tô vivendo muita coisa, acho que eles ainda teriam muita coisa pela frente. (Entrevistado 10)

Sobre isso, Menin e Pettenon (2015), pontuam que o falecer de pessoas dessa idade causa um sofrimento mais acentuado pelo fato de se referir ao começo de uma vida, onde dessa forma, a morte da criança causa maior abalo que a do idoso, pois é vista como a interrupção do ciclo vital. Em determinadas circunstâncias, aspectos como sexo, idade e semelhanças físicas, levam o estagiário a associar o paciente a um ente querido ou a ele mesmo, fazendo-o refletir sobre tal situação (Costa, Poles, \& Silva, 2016).

Outro processo de morrer também citado pelos estagiários como causador de fortes emoções e dificuldades, foi a morte de pacientes oncológicos, onde segundo eles, são pacientes que enfrentam um tratamento longo e doloroso, buscando a cura da doença, que nem sempre é possível, como mostra as falas dos depoentes:

Creio eu que pacientes oncológicos que são aqueles que não tem morte súbita e luta bastante pela vida. (Entrevistado 4)

\section{Pacientes oncológicos, porque é uma situação que o paciente fica muito debilitado, sofre muito. (Entrevistado 7)}

Conforme estudo realizado no México por Marván, Oñate-Ocaña, Santillán-Doherty, e Álvarez-del Río, (2017), cuidar de pacientes com doenças oncológicas e em fase terminal acarreta grande esforço emocional. Essa relação emocional se deve à longa duração do tratamento e às hospitalizações frequentes do paciente, desse modo, a compreensão sobre a mortalidade do câncer provoca dificuldades no enfrentamento de tal realidade (Macedo, Mercês, Silva, \& Sousa 2019).

\section{Considerações Finais}

Este estudo permitiu constatar que os estagiários de enfermagem têm dificuldades em lidar com a morte e o luto, não sendo preparados na graduação para vivenciá-los. Com relação aos sentimentos despertados diante da morte, constatou-se a impotência, tristeza, fracasso, frustração, dor, angústia e frieza. Assim, tentando proteger-se, os acadêmicos criam mecanismos de defesa, tais como a aceitação, racionalização, religiosidade, distanciamento e negação. Percebeu-se, também, que a compreensão deles frente a finitude da vida está relacionada às experiências pessoais de cada um, entretanto, notou-se que a morte de crianças, jovens e pacientes oncológicos são as mais difíceis de lidar.

Em razão dos aspectos mencionados, o estudo aponta para a importância de introduzir na grade curricular disciplinas que abordem o processo de morte/morrer e luto, como a tanatologia, e de realizar reflexões acerca da temática de modo transdisciplinar e multidisciplinar, dando destaque às questões emocionais. É essencial, também, que haja uma capacitação dos docentes para que estes tenham uma melhor abordagem ao trabalhar o assunto. Além disso, se faz necessário uma implantação do tema nos hospitais por intermédio da educação permanente.

Evidencia-se que o estagiário de enfermagem busque realizar cursos e se aperfeiçoar ao decorrer de sua vida profissional para adquirir aprendizados sobre como lidar com situações de terminalidade, prestando assistência de qualidade, e compartilhando conceitos e experiências. O apoio psicológico também se faz imprescindível diante do enfrentamento do processo de morte e morrer, tendo como intuito fornecer conforto e suporte emocional.

Como limitação deste estudo, destaca-se que ele foi realizado com estagiários de enfermagem de uma única Universidade, pois somente esse local possuía o público alvo que correspondia aos critérios de inclusão da pesquisa, restringindo assim, os resultados. Além disso, por se tratar de uma temática delicada, algumas pessoas não aceitaram participar da pesquisa, dificultando o alcance da amostra.

Este estudo abre caminhos para novas investigações voltadas àqueles que lidam com a morte e o luto no ambiente 
profissional, para assim, desconstruir alguns paradigmas existentes e introduzir técnicas eficientes que os auxiliem a enfrentar essa realidade. Para trabalhos futuros, seria válido a produção de pesquisas com uma amostra de diferentes Instituições, que permitisse enriquecer os dados encontrados neste estudo.

\section{Referências}

Araújo, R. M., Álvares, A. C. M., \& Jesus, A. L. S. (2018). O impacto do processo de finitude e morte de pacientes no cotidiano do profissional de enfermagem. Rev Inic Cient e Ext., 1(4), 400-404.

Bandeira, D., Cogo, S. B., Hildebrandt, L. M., \& Badke, M. R. (2014). A morte e o morrer no processo de formação de enfermeiros sob a ótica de docentes de enfermagem. Texto \& Contexto - Enfermagem, 23(2), 400-407.

Benedetti, G. M. S., Oliveira, K., Oliveira, W. T., Sales, C. A., \& Ferreira, P. C. (2013). Significado do processo morte/morrer para os acadêmicos ingressantes no curso de enfermagem. Revista Gaúcha de Enfermagem, 34(1), 173-179.

Costa, Á. P., Poles, K., \& Silva, A. E. (2016). Formação em cuidados paliativos: experiência de alunos de medicina e enfermagem. Interface, 20(59), 10411052 .

Freitas, T. L. L., Banazeski, A. C., Eisele, A., De Souza, E. N., Bitencourt, J. V. O. V., \& Souza, S. S. (2016). O olhar da Enfermagem diante do Processo de Morte e Morrer de pacientes críticos: uma revisão integrativa. Enfermería Global, (41), 335-347.

Huber, D. J., Salvaro, M. S., Medeiros, I. S., \& Soratto, M. T. (2017). Desafios e conflitos éticos vivenciados pela equipe de enfermagem com paciente em processo de morte e morrer. Revista Inova Saúde, 6(2), 50-72.

Lamb, F. A., Beck, C. L. C., Coelho, A. P. F., Bublitz, S., Aozane, F., \& Freitas, P. H. (2017). Estratégias defensivas de trabalhadoras de enfermagem em pronto socorro pediátrico. Rev Rene, 18(4), 453-460.

Macedo, A., Mercês, N. N. A., Silva, L. A. G. P., \& Sousa, G. C. C. (2019). Estratégias de enfrentamento dos profissionais de enfermagem frente à morte na oncologia pediátrica: revisão integrativa. Res. Fundam. Care Online, 11(3), 18-724.

Marván, M. L., Oñate-Ocaña, L. F., Santillán-Doherty, P., \& Álvarez-del Río, A. (2017). Facing death in the clinical practice: a view from nurses in Mexico. Salud Pública de México, 59(6), 675-681.

Menin, G. E., \& Pettenon, M. K. (2015). Terminalidade da vida infantil: percepções e sentimentos de enfermeiros. Rev. bioét., Brasília, 23(3), 608-614.

Muñoz-Pino, I. P. (2014). Experience of nursing students upon their first care encounter with terminally ill patients. Invest Educ Enferm., 32(1), 87-94.

Nunes, F. N. L. Araújo, K. M., \& Silva, L. D. C. (2016). As evidências sobre o impacto psicossocial de profissionais de enfermagem frente à morte. R. Interd., 9(4), 165-172.

Oliveira, E. S., Agra, G., Morais, M. F., Feitosa, I. P., Gouveia, B. L. A., \& Costa, M. M. L. (2016). O processo de morte e morrer na percepção de acadêmicos de enfermagem. Rev Enferm UFPE, 10(5), 1709-1716.

Pereira, F. C. S. M., Carvalho, I. C. C. M., Vale, L. M. S., Silva, N. C., \& Morais, E. R. (2014). Acadêmico de enfermagem frente à morte no campo de prática hospitalar. R. Interd., 7(4), 124-130.

Potter, P., \& Perry, A. G. (2013). Fundamentos de Enfermagem. Rio de Janeiro: Elsevier.

Rosa, D. S. S., \& Couto, S. A. (2015). O enfrentamento emocional do profissional de enfermagem na assistência ao paciente no processo da terminalidade da vida. Revista Enfermagem Contemporânea, 4(1), 92-104.

Salum, M. E. G., Kahl, C., Cunha, K. S., Koerich, C., Santos, T. O., \& Erdmann, A. L. (2017). Processo de morte e morrer: desafios no cuidado de enfermagem ao paciente e família. Rev. Rene, 18(4), 528-535.

Sant'Ana, R. S. E., Santos, E. R., Menezes, T. M. O., Pereira, A., \& Santana, M. T. B. M. (2013). A prática assistencial do enfermeiro frente ao processo de morte e morrer: uma revisão integrativa da literatura. Rev. Enferm. UFPE, 7, 919-927.

Santos, R. A., \& Moreira, M. C. N. (2014). Resiliência e morte: o profissional de enfermagem frente ao cuidado de crianças e adolescentes no processo de finitude da vida. Ciência \& Saúde Coletiva, 19(12), 4869-4878.

Sartori, A.V., \& Battistel, A. L. (2017). A abordagem da morte na formação de profissionais e acadêmicos da enfermagem, medicina e terapia ocupacional. Cadernos Brasileiros de Terapia Ocupacional, 25(3), 497-508. 